\title{
Application of a Shaping Technique to Increase On-Task Behavior Duration in Children with ADHD
}

\author{
Amatul Firdausa Nasa ${ }^{a}$, Sri Redatin Retno Pudjiati ${ }^{b^{*}}$, Mita Aswanti \\ Tjakrawiralaksana ${ }^{\mathrm{b}}$
}

${ }^{\mathrm{a}}$ Faculty of Psychology, University of Indonesia, Depok, 16424, Indonesia; ${ }^{\mathrm{b}}$ Department of Developmental Psycohlogy, ${ }^{\mathrm{a}}$ Faculty of Psychology, University of Indonesia, Depok, 16424, Indonesia

*Corresponding author:

Sri Redatin Retno Pudjiati

Developmental Psychology Department

Faculty of Psychology, Universitas Indonesia

Jl. Lkr. Kampus Raya, Depok, Jawa Barat

Indonesia, 16424

Tel.: +62 217270004

Email address: retno-pj@ui.ac.id 


\title{
Application of a Shaping Technique to Increase On-Task Behavior Duration in Children with ADHD
}

\begin{abstract}
In general, children with ADHD have difficulty performing on-task behaviors. This relates to their difficulty of sustaining their attention for a long time. Difficulty in maintaining attention level means that children with ADHD often experience poor academic performance and academic failure. To improve their ability to sustain their attention, treatment is required to increase on-task behaviors. Behavior modification is a widely used intervention that is proven effective for treating children with ADHD. This research used a shaping technique to increase the duration of on-task behavior in an 11 year-old diagnosed with ADHD with combined presentation. The research studied the boy's ability to listen to a story and answer questions based on the story. The results showed that a shaping technique can increase the duration of on-task behavior in children with ADHD from 1 minute during the baseline up to 10 minutes during the post test. The maximum duration achieved was $80 \%$ of the target duration (12 minutes). During the intervention program, increased duration occurred gradually from 2 until 12 minutes and decreased until 10 minutes post-intervention.
\end{abstract}

Keywords: attention-deficit/hyperactivity disorder (ADHD); behavior modification; ontask behavior; shaping technique

\section{Introduction}

The ability to regulate and maintain attention is an important ability for children to optimize. This ability usually begins to appear at school age (6-12 years) (Berk, 2006). However, some children at this age have difficulty regulating and maintaining their attention (Berk, 2006). Most children with attention problems met the diagnosis criteria for Attention-Deficit/Hyperactivity Disorder (ADHD) (Rabiner, Murray, Skinner, \& Malone, 2010), and about 3\%-9\% of schoolaged children were diagnosed with ADHD (Besly, 2002).

The characteristics of ADHD include difficulty focusing attention (i.e., inattention) and/or persistent hyperactivity/impulsivity that interfere with the individual's functional development (American Psychiatric Association, 2013). At school age, inattention is seen through the individual having difficulty concentrating on tasks, failing to follow instructions, and not listening while others are talking (Lee \& Song, 2015), while the hyperactive impulsive is displayed with behaviors such as throwing out an answer before a question is finished, speaking or answering before his/her turn, interrupting conversation, and talking excessively (McInnes, Humphries, Hoo-Johnson, \& Tannock, 2003).

The symptoms displayed by a child with ADHD are related to interference with executive function (Kofler, 2009). Disturbance in this area causes the difficulty of staying focused on task while successfully ignoring other unrelated stimuli (Hugdahi, Westerhausen, Alho, Medvedev, Laine, \& Hamalainen, 2009). In many studies, inattention in ADHD children is often operationalized as off-task behavior (Kofler, Mark, \& Alderson, 2008). To be successful in the academic world, a child must be able to pay attention to the task and/or display consistent ontask behavior (Axelrod, Zhe, Haugen, \& Klein, 2014). According to Graham-Day, Gardner and Hsin (2010), on-task behavior is defined as behavior in which the child focuses his attention on 
the task or material without performing other activities unrelated to the task. Therefore, the child is said to display on-task behavior if he does not display off-task behavior while completing a task (Cipiti, 2010).

The inability of children with ADHD to display on-task behavior is the main reason they experience academic difficulties and failures (Harpin, 2005; Frazier, Youngstrom, Glutting, \& Watkins, 2007). In addition, the presence of comorbidity with learning disorders (specific learning disorders) further increases the likelihood that children with ADHD will display off-task behavior (Miranda, Jarque, \& Tarraga, 2006). Students with ADHD usually fail at performing tasks requiring organizational capabilities due to an ineffective use of the higher order processes: working memory, working fluently, being alert, and monitoring their work. These deficits appear to especially affect children with ADHD who present comorbid LD (Seidman, Biederman, Monuteaux, Doyle, \& Faraone, 2001). Children with ADHD who present as comorbid with specific learning disorders have difficulty with the learning process and need to receive special education. If they do not receive it, they usually fail at performing tasks and have low motivation for completing tasks (Miranda, Jarque, \& Tarraga, 2006). According to Young and Amarasinghe (2010), ADHD with comorbidity with learning disorders is closely related to low academic achievement in children.

In turn, low academic achievement or failure makes children with ADHD more likely to feel frustrated and inadequate, and to judge themselves more negatively (Gagliano, Lamberti, Siracusano, Cruffo, Boncaddo, Maggio, Rosino, Cedro, \& Germano, 2014). They also lose confidence in their own abilities (Lebowitz, 2016) and tend to have low self-esteem (Firmin \& Phillips, 2009).

Academic failure typically experienced by children with ADHD also makes them subject to negative judgment by parents, teachers, and peers (Lebowitz, 2016). Parents of children with ADHD tend to evaluate their children's abilities more negatively than how they judge normal children (Eisenberg \& Schneider, 2007). Teachers' assessment of children with ADHD who are experiencing difficulty in academics also tends to be more negative (Lebowitz, 2016). In addition, children with ADHD are often negatively labeled by friends as careless, crazy, weird, or stupid, and this often ends in avoidance of friendship or playtime. These labels are applied because children with ADHD display symptoms that clearly affect their performance and their interactions at school (Lebowitz, 2016). Children with ADHD are described as having difficulty sustaining attention to relevant stimuli and typically showing impulsive responses to irrelevant stimuli (Brady \& Kubina, 2010). Being labeled negatively others causes children with ADHD to have a negative self-concept and difficulty making friends (Rutherford, DuPaul, \& Jitendra, 2008).

$\mathrm{R}$ (initial name) is an 11 year-old boy diagnosed with ADHD criteria with combined presentation and comorbidity with the Specific Learning Disorder based on DSM-5. His problems in society and academically are associated with his diagnosis. His academic achievements are far below that of his friends at school. He has difficulty reading, writing, and counting. The teacher must explain the material more verbally to him because he complains and often refuses when asked to read by himself. In addition, he assesses and captures more information more quickly when it is submitted orally than when he reads alone. He still needs to be accompanied in order to complete 
a task at hand. His easily distracted attention prevents him from completing tasks independently. His difficulties with learning cause him to judge himself negatively. He becomes less confident with his ability and is more likely to give up easily when facing difficulties or obstacles, even before trying to succeed.

Children with ADHD need treatment to improve their ability to maintain their attention to performing tasks and increasing the duration of on-task behavior. With an increase in on-task behavior, their ability to learn also increases (Lantz, McKenna, Price, \& Stralow, 2007), and this is followed by improving academic achievement (Green, Long, Green, Iosif, Dixon, Miller, \& Schweitzer, 2012). In addition, their confidence and self-esteem improve as a result (Harpin, Mazzone, Raynaud, Kahle, \& Hodgkins, 2016). Children with ADHD who are able to exhibit increased attention to task can also be marked by an increase in the duration of on-task behavior (McDowell \& Keenan, 2001 in Brady \& Kubina, 2010).

Behavior modification is a widely used and proven effective treatment for children with ADHD. This intervention is supported by empirical evidence of success in reducing ADHD symptoms (Halperin \& Healey, 2011). The use of behavior modification has been shown to improve on-task behavior in children with ADHD (Fabiano \& Pelham, 2003; Halperin \& Healey, 2011) as well as in children with ADHD who have comorbidities with learning disorders (Hawkins \& Axelord, 2008). This current research involved a child with difficulties in reading comprehension. His teacher must explain the material verbally because he complains and refuses to read by himself. In addition, he is able to assess and capture more information more quickly when delivered orally than when he is asked to read alone. This technique was chosen for the intervention to improve R's on-task behavior because of its proven effectiveness in previous studies. Because of his difficulty sustaining attention to task are often reinforced by the positive consequences he gets from the environment (spared or relieved of duty). In addition, he has also never been trained to develop skills of displaying positive behavior while learning. According to Pelham and Fabiano (2008), behavior modification is an early intervention that should be given to children with ADHD.

In this research, the behavior modification technique used is a shaping technique. Shaping is a gradual method of forming new behavior by being divided into several steps (Domjan, 2010). In shaping techniques, prompts are given according to the individual child's needs as he is learning a skill (Ciccarelli \& Meyer, 2006). The prompt itself is a tool or a stimulus used to increase the likelihood of the desired behavior (Martin \& Pear, 2007). Once the child has mastered the skill at a certain stage, he or she receives positive reinforcement in the form of either fun or praise. The use of prompt is gradually reduced so that eventually the child can perform the necessary skills independently (Ciccarelli \& Meyer, 2006).

The use of a behavior modification approach using shaping and positive reinforcement techniques with a token system was found to successfully improve a child's ability to accomplish tasks by increasing on-task behavior in children (Ho, Chien, \& Wang, 2011). In addition, according to research conducted by Athen and Vollmer (2007), known shaping techniques and the use of token economy as reinforcement successfully improved task engagement as seen by increased duration of on-task behavior in 4 school-aged children with learning disorders. 
The purpose of this study is to examine whether the application of shaping techniques can increase the duration of on-task behavior in children with ADHD. Improved on-task behavior in this study is seen by an increase in the duration of on-task behavior displayed by the child in the face of performing a task in stages. The task given in this research was for the child to listen to stories recorded by the researchers. This task was chosen because listening to a story is one method of increasing the attention range in children with ADHD (Paxton \& Shoemake, 2007). Because of the difficulties children with ADHD typically experience in reading, many studies provide listening tasks instead of reading tasks to examine the child's comprehension (Miller, Keena, Betjemann, Willcutt, Pennington, \& Olson, 2013). This is because children with ADHD have more difficulty maintaining visual-spatial information than verbal information in their working memory as they complete tasks (McInnes, Humphries, Hogg-Johnshon \& Tannock, 2003). It is easier for children with ADHD to remember verbally delivered information than visually delivered information (Kofler, 2009; Green, Long, Green, Iosif, Dixon, Miller, Fassbender, \& Schweitzer, 2012).

Research studies where children with ADHD were given a listening task are still limited in number (McKenna, Price, and Stralow, 2007). Therefore, this researcher was especially interested in studying whether this would be an effective method of improving R's on-task behavior, as well as seeing whether it would fit his particular needs. In addition, it is expected that providing these interventions will produce a positive outcomes for the participant. According to Lantz, McKenna, Price, and Stralow (2007), listening skills should be taught because these skills are essential to the child's success, not only in school but also in life.

In this study, the length of the story was adjusted to the target duration at each stage as determined by using the shaping technique. Stories that were selected for use in this study are read by the researchers at an appropriate loudness level with a rather slow tempo, and they were recorded using a voice recorder. When the child reaches the target, he receives a reinforcement of tokens (stickers) that he can exchange with back-up reinforcement at the end of the session; he will also receive social reinforcement in the form of praise from the researchers. The research was conducted at the clinic of Faculty of Psychology, University of Indonesia. This was done in order to control environment stimuli that can distort the child's attention while he is listening to the story. According to Paxton and Shoemaker (2007), if using a hearing activity as a task, one must be sure to choose a quiet room that is free of distracting stimuli.

\section{Methods}

\section{Participant}

The participant was an 11 year-old boy who met the diagnostic criteria of ADHD combined type with specific learning disorder. His academic skills tended to fall far behind other children of his age. In the process of learning both at home and at school, he often had difficulty sustaining his attention, so he was not able to complete tasks. His average completion rate for tasks was only $50 \%$ of the tasks assigned and still required the direction, supervision, and guidance from his parents at home and from his teachers at school.

$\mathrm{R}$ was often unfocused and displayed behavior unrelated to the task (off-task behavior) when considerable concentration was required. He also displayed this behavior when he faced difficult 
tasks or if he found a task not naturally easy to do well. He often displayed off-task behavior such as standing up from his seat, looking around the room, playing with objects around him, daydreaming, talking about unrelated topics, complaining, or showing anger. Because of these behaviors, he was unable to complete tasks. He had to be constantly reminded and continuously supervised in order to complete a task. In addition, when he had complained or showed anger, the parent or teacher did not typically demand that he complete the task, so he was released from making the effort.

\section{Research Design}

The research design used was a single-case design using type A-B. This design involved only one participant, and the measurements were repeated until a stability that could be used as a baseline was reached (condition A). After the intervention was given, the measurements were taken again to see what has changed (condition B) (Fraenkel \& Wallen, 2009). In this research, the A-B design was used to learn the increased duration of on-task behavior in children with ADHD after receiving an intervention using a shaping technique.

\section{Measures}

This study used 4 instruments for collecting data: an ABC Observation Sheet, a Reinforcement Inventory, a Behavioral Observation Sheet, and an Intervention Implementation Sheet. Here's an explanation of each instrument:

\section{ABC Observation Sheet (Antecedent - Behavior - Consequences)}

The ABC Observation Sheet was an initial assessment of the behavioral function that this intervention targeted in the behavior modification program. This observation sheet was adapted from Miltenberger (2012) based on the needs of this study. This sheet was used as an assessment by noting the description of behavior, antecedents, and consequences each time the targeted behavior appeared. Observations were made when the participant did the task at home, at school, or at the clinic. The data obtained from the ABC Observation Sheet was used to develop hypotheses related to behavioral functions.

\section{Reinforcement Inventory}

Reinforcement inventory was used to identify objects and activities favored by the child that could be used as reinforcement in the behavior modification program. This instrument was adapted from the Institute of Applied Behavior Analysis (IABA, 1993). The reinforcement inventory sheet was used as an interview guide for parents at the initial assessment stage. Data obtained from the reinforcement inventory was used to determine what items would be used in the behavior modification program. The list of back-up reinforcements was prepared based on interview results using reinforcement inventory and agreed-upon by the parents, child, and the researcher.

\section{Behavior Observation Sheet}

Researchers designed an observation sheet to use while recording the duration of on-task behavior while the participant worked on the task. This sheet was used to collect data at the baseline and post-test stages. The method used was continuous. At baseline, recording began at the time the participant first displayed on-task behavior and ended when he displayed off-task behavior. The recording began again each time on-task behavior was displayed. In addition, behaviors displayed while the participant listened to stories were recorded to gain additional 
insight about his off-task behaviors. The researcher also recorded questions that he answered correctly after the completion of the story by ticking $(\sqrt{ })$ on the respective question number.

\section{Intervention Implementation Sheet}

The function of the intervention implementation worksheet was to record the duration of on-task behavior the participant showed during a task while the intervention was given. The researchers designed these sheets based on the research needs. On this sheet, the duration recording was only done once at the beginning of his displaying on-task behavior and not again until the beginning of his display of the off-task behavior. If he succeeded in reaching the time target, then the researcher ticked $(\sqrt{ })$ the provided column; otherwise the researcher marked a cross $(\mathrm{X})$ and added a caption for the actual duration $\mathrm{R}$ accomplished. Also on this sheet was recorded the number of questions that he successfully answered, the number of successful tokens in each experiment, the type of back-up reinforcement, and short observations related to each session.

\section{Procedure}

The goal of this intervention was to increase the duration of the child's on-task behavior with the goal of reaching 12 minutes. The target duration was determined according to the consideration that an average child's attention span is their chronological age plus one (Student Coalition for Action in Literacy Education, 2006).

Interventions were held over 5 consecutive days. The location was a clinic room that had been in set aside for research purposes. This location was selected with the goal of minimizing distractions and disturbances from the environment that could interfere with participant concentration.

\section{Assessment}

This phase began with the initial data collection. The researcher conducted behavior analysis related to the participant's on-task behavior. At this stage, the researcher conducted interviews to obtain other supporting data such as environmental factors, how the instructions was delivered, and understanding what reinforcements would be effective for the participant. Researchers also observed the target behavior for this intervention. After that, researcher asked the parent's for their consent to engage in the research; this was followed by providing them with informed consent information in writing.

\section{Baseline}

Sessions for baseline were done four times over two days (on one day there were two baselines done) in the clinic room. Each session lasted approximately 15-20 minutes. The participant listened to a story for a duration of \pm 12 minutes that was previously recorded by researchers using a voice recorder. The researchers prepared four different stories so that there would be one story for each session. The stories were selected from the participant's school subject materials and contained general information. While listening, the researcher counted the participant's time displaying on-task behavior by using a stopwatch. The timing was stopped when he displayed off-task behavior and started again when he performed on-task behavior. The researcher also recorded behaviors that the participant displayed while listening to the story. After the story recording, the researcher asked five questions verbally and received verbal answers from the participant. From the baseline, it was found that the participant was able to show an average 
duration of on-task behavior for one minute and could answer an average of two questions for every story.

\section{Intervention}

The researchers provided initial psychoeducation to the parents about the behavioral modification approach that would be used in the intervention. The behavior modification technique used in this program was the shaping technique. Duration was the behavior dimension formed using the shaping technique in this study. Duration shaping is done by increasing the amount of time the child displayed the on-task behavior gradually until it reached the expected amount of time at the end of the program (Evereett \& Cannon, 2015; Martin \& Pear, 2007).

The program implementation design in this intervention used a shaping technique referred to in research conducted by Menditto, Badwin, O'Neal and Beck (1991) whose participants had attention disorders. Increased duration of on-task behavior was done gradually and took 2-3 trials per session before the target duration would be increased in the next session (Menditto, et al 1991). In this program, session one and two had three trial times, whereas in sessions 3-5 there were two trial times. After completing one trial, the participant was given time to rest before proceeding to the next trial.

This program also involved the use of prompt and positive reinforcement. Prompts used were verbal and extrastimulus. Verbal prompts were given by verbally instructing $\mathrm{R}$ to listen the story carefully and reminding him when he was not displaying proper on-task behavior. Extrastimulus prompts used were visual (pictures) that helped to describe the behaviors expected from him, behaviors that he should not display while listening to the story in order to get reinforcement, reinforcement images and how to exchange them with tokens, and sheets for placing the stickers. The other extrastimulus prompts were an alarm used to help the child know the expected time targets for displaying on-task behavior.

Positive reinforcement in this program was provided in two forms: token economy and social reinforcement. Token economy was given in the form of a sticker that the participant would get if he successfully reach the target duration and target number of correct questions answered. Tokens could be redeemed at the end of the session for an agreed-upon back-up reinforcement. Social reinforcement was given in the form of praise by the researchers such as "Wow, you are great, you were willing to try!," "You can do it, if you want to try!," "Great!/Well done; you can answer the questions!" Every time he reached the target duration and managed to answer the questions correctly. A summary of the intervention implementation is shown in Table 1: 
Table 1

\begin{tabular}{|c|c|c|c|c|c|c|}
\hline Session & $\begin{array}{c}\text { Number of } \\
\text { trials }\end{array}$ & $\begin{array}{c}\text { Target } \\
\text { of } \\
\text { duration }\end{array}$ & $\begin{array}{c}\text { Break } \\
\text { time } \\
\text { between } \\
\text { trials }\end{array}$ & $\begin{array}{l}\text { Target of } \\
\text { the } \\
\text { correct } \\
\text { answer } \\
\text { each trial }\end{array}$ & $\begin{array}{l}\text { Number } \\
\text { of } \\
\text { token } \\
\text { each } \\
\text { session }\end{array}$ & $\begin{array}{c}\text { Back-up reinforcements and Number of } \\
\text { tokens to redeem }\end{array}$ \\
\hline 1 & $3 \times$ trial & $\begin{array}{c}2 \\
\text { minutes }\end{array}$ & $\begin{array}{c}2 \\
\text { minutes }\end{array}$ & 1 of 2 & 6 & $\begin{array}{l}6 \text { token = Lego of superhero in mini } \\
\text { size } \\
5 \text { token = Download games } \\
4 \text { token = Superhero stationery series } \\
3 \text { token = Food (pempek) } \\
2 \text { token = Changing sticker (the } \\
\text { pictures can change) } \\
1 \text { token = Sticker with Spiderman } \\
\text { picture }\end{array}$ \\
\hline 2 & $3 \mathrm{x}$ trial & $\begin{array}{c}4 \\
\text { minutes }\end{array}$ & $\begin{array}{c}3 \\
\text { minutes }\end{array}$ & 2 of 3 & 6 & Same with session 1 \\
\hline 3 & $2 \mathrm{x}$ trial & $\begin{array}{c}6 \\
\text { minutes }\end{array}$ & $\begin{array}{c}5 \\
\text { minutes }\end{array}$ & 3 of 4 & 4 & $\begin{array}{l}4 \text { token }=\text { Lego of superhero in mini } \\
\text { size } \\
3 \text { token }=\text { Download games } \\
2 \text { token }=\text { Superhero stationery series } \\
1 \text { token }=\text { Food (pempek) }\end{array}$ \\
\hline 4 & $2 \mathrm{x}$ trial & $\begin{array}{c}9 \\
\text { minutes }\end{array}$ & $\begin{array}{c}7 \\
\text { minutes }\end{array}$ & 4 of 5 & 4 & Same with session 3 \\
\hline 5 & $2 \mathrm{x}$ trial & $\begin{array}{c}12 \\
\text { minutes }\end{array}$ & $\begin{array}{c}10 \\
\text { minutes }\end{array}$ & 5 of 6 & 4 & Same with sessions $3 \& 4$ \\
\hline
\end{tabular}

\section{Post Intervention}

Post intervention was done one day after giving each intervention. The researcher performed the measurement of on-task behavior as the participant listened to the story for 12 minutes. Data obtained at this stage (duration of attention/on-task behavior) were compared with data obtained at the baseline stage to determine changes in the duration of on-task behavior displayed by the participant after the intervention.

\section{Data Analysis}

The results of data analysis were obtained from the comparison of the on-task behavior duration displayed by the participant at baseline and post-intervention stages. Interventions were declared successful when the duration of on-task behavior (participant could focus on the story being read) in the post-intervention stage increased to $100 \%$ of the average duration at baseline or $75 \%$ of the targeted duration (Kofler, Rapport \& Alderson, 2008). This meant that the intervention could be deemed successful when the participant could show on-task behavior during 10 minutes in a reading session without being given the intervention anymore. 


\section{Results}

\section{Intervention}

During the intervention, the participant showed an increase in duration of on-task behavior when faced with the task of listening to stories. This increase in duration occurred gradually from two minutes in length to 12 minutes. The duration of improved on-task behaviors that appeared during the intervention is illustrated in Figure 1. In addition, he showed an increase in his comprehension of reading content marked by an increase in the number of questions that he could correctly answer from the first session to the final session. This increase is illustrated in Figure 2.

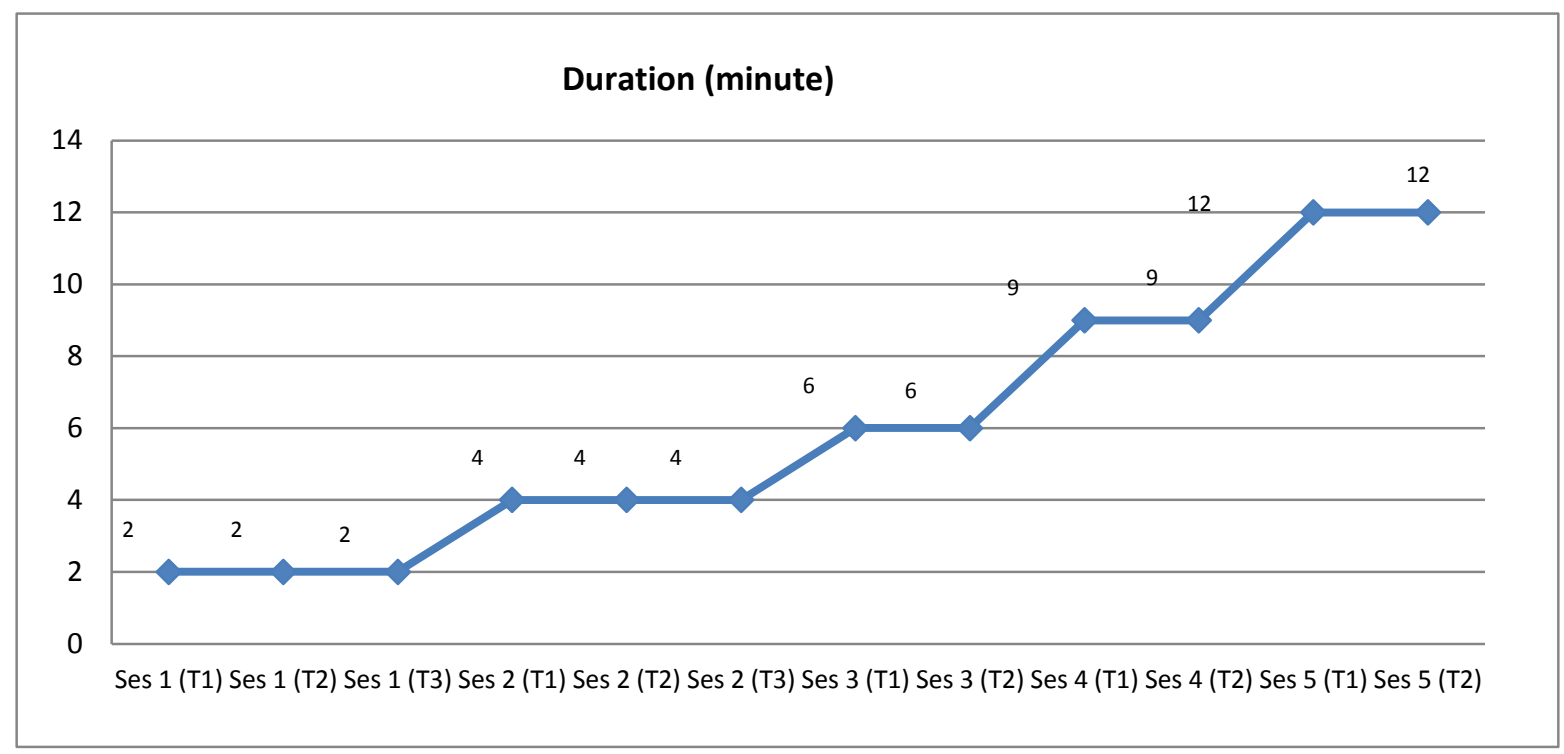

Figure 1. Duration of on-task behavior per session (in minutes)

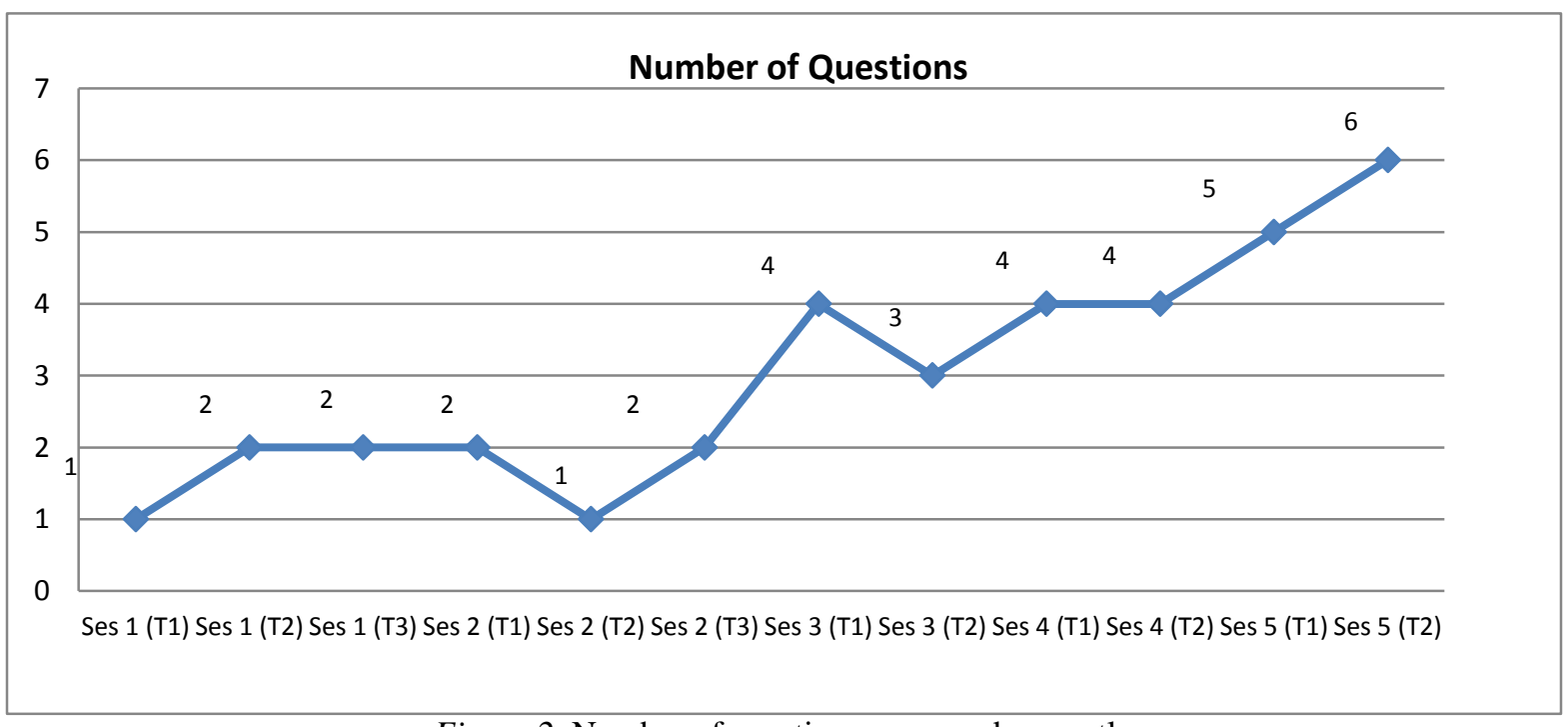

Figure 2. Number of questions answered correctly 
As seen in Figure 2, in the beginning, the participant was only able to answer one out of two questions. But with the longer story duration and the increasing number of accompanying questions that had to be answered correctly, the number of questions that he was able to answer also increased. Nevertheless, his performance decreased twice from the previous stage; that is, in the second session of the second trial and in the third session of the second trial. In the second trial of the second session (story duration of four minutes), he failed to answer the target number of questions correctly, so he did not get the token. This failure caused him to have an outburst, but it did not reduce his performance in the next trial. Meanwhile, in the second trial in the third session (story duration of six minutes), he managed to answer three questions and received the token because he reached the target of three correct answers.

\section{Post Intervention}

A measurement comparison of on-task behavior duration at baseline and post-intervention also showed significant improvement. The result from the post intervention was that the participant displayed a $100 \%$ increase in duration from the baseline stage; that is, up to 10 minutes. The increase in duration of the participant's on-task behavior from the baseline stage, intervention stage, and post-intervention stage is illustrated in Figure 3:

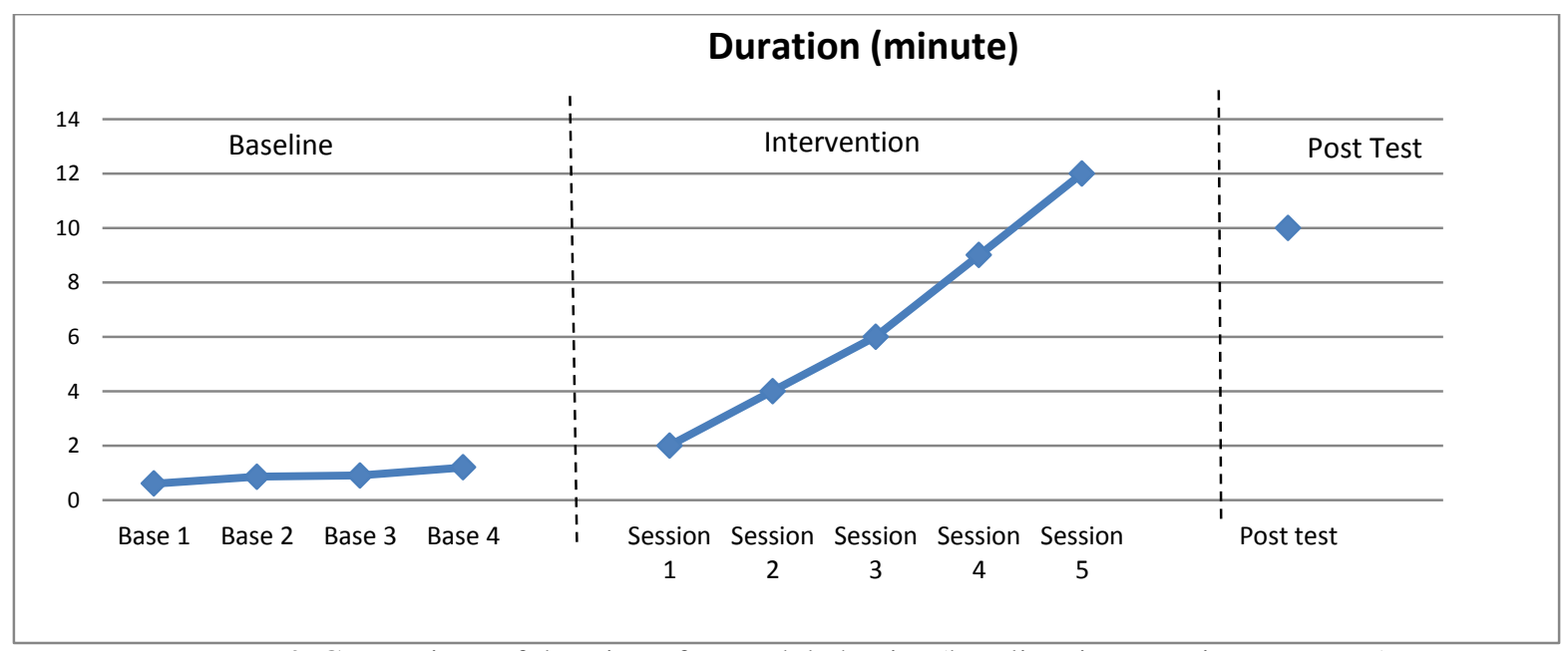

Figure 3. Comparison of duration of on-task behavior (baseline, intervention, post-test)

\section{Discussion}

The results showed that the application of a behavior modification principle using a shaping technique can increase on-task behavior duration in school-aged children with combined type ADHD. The results of this study support the results of several previous studies that used behavioral modification to improve on-task behavior in children with ADHD (Mathes \& Bender, 1998; Hawkins \& Axelrod, 2008; Athens \& Vollmer, 2007; Fabiano \& Pelham, 2003; Halperin $\&$ Healey, 2011). From this study's post-intervention results, we found that the participant was able to continue displaying on-task behavior for 10 minutes without any intervention. The duration at which he succeeded was only $80 \%$ of the target duration goal (12 minutes), which refers to the minimal attention range seen in 11 year-old children (SCALE, 2006). These results align with the results of research conducted by Kofler, Mark and Alderson (2008), who found that most children with ADHD are able to display on-task behavior for about $75 \%$ of the time 
average children with normal development can achieve. This suggests that the intervention improved the participant's on-task behavior duration.

At the time of the intervention, $\mathrm{R}$ succeeded in reaching the 12-minute target duration, but was not able to do so during the actual post-test; at that point, the duration declined to 10 minutes. The decrease in duration may have been due to the different environmental setting used for the intervention and the post test. That is, the post-test was done in one room at the participant's home. In contrast to the minimal distractions of the examination room, in the room at home there were a number of visual stimuli, including items and photos/pictures displayed on the walls that may have distracted the participant. According to Godwin, Almeda, Petroccia, Baker, and Fisher (2013), an environment filled with visual stimuli in large numbers can lead to off-task behavior more than environments with minimal visual stimuli. At the post test, in the $10^{\text {th }}$ minute, the participant turned his gaze in another direction for 30 seconds, but after he was able to refocus until the story was finished. This shows that he was actually able focus his attention for 12 minutes in a minimal distraction environment but that the ability declined while working in a more distracting environment.

This increase in his duration of on-task behavior was also followed by an increase in his comprehension of the content of the story as evidenced by the increasing number of questions that he was able to answer appropriately. He was even capable of conveying information beyond the story-related questions at the fourth and fifth sessions. This shows that he was not just sitting and listening to the story, but that he was also focused on the story. The purpose of the questions asked after he listened to the story was to see how focused he was while listening. Correct answers indicated better focus. His ability to answer questions correctly was also related to his comprehension ability. Therefore, in this study, the stories were chosen according to the child's ability (material from $4-6^{\text {th }}$ grade) and the questions asked were factual, such as what, who, where and when questions as opposed to how and why. According to McInness et al (2003), children with ADHD find it easier to capture factual information (what, where, when, and who) than cause and effect information or any question requiring the ability to conclude/analyze (why \& how). The ability of a child with ADHD to remember factual information in the narration equals that of the average normal child.

The success of this intervention program was influenced by several factors. The first is related to the shaping technique used. In previous studies, some behavioral modification approaches using shaping techniques had been found to improve on-task behavior in school-age children (Ho, Chien, \& Wang, 2011), increasing the attention span by increasing participants' on-task duration behavior (Menditto, Baldwin, O'Neal, \& Beck, 1991; Silverstein, Menditto, \& Stuve, 2001), and had also been shown to be effective in increasing on-task behavior in children with learning disorders (Athens \& Vollmer, 2007). In this research, a shaping technique was used to gradually increase the R's duration of on-task behavior, starting from 1 minute (baseline) and eventually reaching 12 minutes. It is evident that the appropriate shaping technique was used with $\mathrm{R}$ because his on-task behavior began at a low duration (1 minute). Therefore, improvement needed to be pursued gradually so as to provide him with a sense of success and increased confidence during the learning process. The strength of a shaping technique is that it enables individuals to gradually learn to master a skill, gaining a sense of accomplishment at each stage before proceeding to a more challenging stage (Silvertein, Meditto, \& Stuve, 2001). 
The use of positive reinforcement in the form of token economy and social reinforcement in this study also proved to have important roles in improving the participant's on-task behavior. In this study, reinforcement was given when the participant displayed appropriate on-task behavior for a particular duration in accordance with the target duration. In children with ADHD, the use of reinforcement systems should focus on rewarding positive behaviors of on-task behavior rather than punishment for negative or off-task behavior (Axelrad, et al, 2011). Some previous research results found that the use of tokens as a technique to provide reinforcement improved positive learning behavior in children with ADHD (DuPaul \& Jimerson, 2014; Firmin \& Phillips, 2009). In addition, the use of a token economy as a positive reinforcement was shown to increase children's motivation to behave appropriately (Robinson, Newby, \& Ganzell, 1981).

Selecting appropriate reinforcement backups and environmental controls related to the provision of reinforcement also support the success of this program. The use of redeemable tokens motivated $\mathrm{R}$ to achieve all targets. $\mathrm{R}$ had one outburst when he failed to get a token in the second trial in the second session, and as a result tried extra hard to focus in order to get the token in the next trial. The use of social reinforcement in the form of praise also had a significant influence on $\mathrm{R}$, especially in giving him a positive sense of himself. $\mathrm{R}$ became more willing to try each task, and more willing to try to make it through each entire task. According to Kercood and Banda (2012), giving praise can increase children's self-confidence and improve their performance as a result.

The use of prompting images also played an important role in improving R's on-task behavior. In this research, the prompting images were used with the goal of facilitating his understanding of the instructions and rules. ADHD children, especially those with comorbidities with specific learning disorders, tend to have difficulty remembering verbal instructions or directions (Duane, 2011). Therefore, aid in the form of drawings can help the child to understand the instructions and remember the rules. The prompts were used at the beginning of every activity started, so $\mathrm{R}$ received clear descriptions of the expected rules and behaviors while listening to the stories. Children with attention problems benefit from clear structures, rules, and expectations delivered before the activity begins (Ackerman, 2004). In addition, the prompting drawings used in this study made use of interesting colors that attract R's attention during the researcher's explanations. Children with ADHD have shown increased attention with the use of colorful visual stimulation, thus improving their on-task performance (Zentall, Falkenberg, \& Smith, 1985).

The second factor was listening to stories for a given duration; this activity also contributed to R's improved on-task behavior. Activities such as listening to stories have been shown to help increase children's attention range (Feitelson, Kita \& Goldstein, 1986; Duane, 2011; Paxton \& Shoemake, 2007). When the child paid attention to the story being read, he became more aware of the content of the story because he had to be attentive to understand the story content (McInness, et al, 2003). In addition, from the results of research conducted by Abikoff, Szeibel and Koplewicz (1996), providing an auditory stimulus can also improve on-task behavior in children with ADHD.

A third factor that also supports the success of this intervention program was the child's personality. $\mathrm{R}$ was quite cooperative and obedient to the rules when reminded. According to Heath, Curtis, and McPherson (2015), ADHD children usually exhibit greater patterns of 
noncompliance. However, $\mathrm{R}$ typically displayed cooperative behavior and followed the rules during the program. At first, he often tried to do what he wanted (e.g., wanting to start listening without a break), but he was obedient and cooperative after being reminded by the researcher. This supported the intervention program because his attitude allowed the program to work according to plan. In addition, although he was easily frustrated and displayed an outburst when he failed, it was still possible to soothe, persuade, and convince him to continue the activity.

The last supporting factor was the external environmental factors associated with minimal distraction. Providing minimal distraction in the room where the activities took place made it possible for $\mathrm{R}$ to concentrate more and successfully focus on the tasks. A minimal distraction setup includes little or no visual decoration, minimal noise, minimal furniture, and comfortable light and temperature levels. Providing a calm and less stimulating environment for children with ADHD to work in is shown to improve their performance while completing tasks (Axelrad, Bender, Bonin, Castle, Hendriksen, Hinton, \& Miller, 2011). Distracting environments that include indoor and outdoor sounds, too many visual displays, or too much furniture can increase the likelihood of their displaying off-task behavior while performing tasks (Godwin, Almeda, Petroccia, Baker, \& Fisher, 2013). In addition, R's parents contributed to the success of the program by being quite cooperative in terms of following the predetermined schedule of the program, as well as not interfering with the back-up reinforcement plan.

The result of this research shows that the application of a behavior modification principle via a shaping technique can increase a child's on-task behavior duration. We have seen that the increase of duration increased from the average of one minute at baseline to 10 minutes after intervention. In addition, there was a $100 \%$ increase in the percentage of R's on-task behavior from the baseline stage (from 1 minute to 10 minutes), and he achieved $80 \%$ of the target duration in the last session of the intervention; that is, he reached only 10 minutes during posttest, but had already successfully reached 12 minutes earlier in the process. In addition, $\mathrm{R}$ displayed an increased understanding about the content of the story; this was marked by the increasing number of questions that $\mathrm{R}$ could answer correctly. Over the course of the intervention, he successfully answered one question in the beginning but was able to answer six questions by the end. Improving his ability to answer questions correctly demonstrates that $\mathrm{R}$ was not just listening but also focusing on each story.

There are some limitations in this study. The measurements performed for this research involved only one rater, so the reliability of the measuring instrument could not be obtained, and therefore the measurement results tend to be more vulnerable to subjectivity. Also, with regard to the selection of story content, there were differences in the number of details provided, which can result in different reactions or abilities as children listen. $\mathrm{R}$ tended to have difficulty maintaining his attention, and he often looked tired when listening to stories containing too much detail, such as multiple places, years, and names. He also tended to be calmer and more focused on stories that he considered interesting. With stories he found more boring, he had more difficulty focusing and was more likely to move around.

In addition, as explained earlier, the selection of minimally distracting environments in this study was one of the factors supporting the success of the intervention program. This indicates the importance of the environment's role; we saw that changes in environmental settings at post intervention in the child's home environment caused his on-task performance to decrease. This is 
important to note because children will face more challenges while at home or school due to the likelihood of experiencing more distraction. Therefore, in order to retain the skills already achieved by the end of the intervention, it would be necessary to generalize the program within the natural setting of the child (Martin \& Pear, 2007). One way to do this is to involve a parent as implementer when the child is studying at home so that this skill can be used in participants' daily lives. The parents would need to be coached by the researcher in order to successfully implement this program at home.

In this study, there was an increase in on-task behavior as measured by the increase in duration achieved, as well as a measurable increase in comprehension based on the number of questions answered correctly. Nevertheless, there may be changes in other behaviors during the intervention that were not measurable in this study. These were internal or covert behaviors that could not be measured directly (Martin \& Pear, 2007). According to Miltenberger (2012), behavior modification techniques not only influence directly observable or overt behavior that is the target of improvement but also directly affect the unmeasured covert behavior in the intervention.

For future research, in the measurement using more than one to do the rating would improve the reliability of research results. Subsequent research could also use different types of stories, such as short stories or fairy tales to see if there is a difference when compared to the use of stories containing general knowledge, as were used in this study. In addition, further studies should also involve fide reinforcement and prompt procedures so that more detailed analysis can be performed.

\section{References}

Abikoff, H., Courtney, M. E. ,Szeibel, P. J., \& Koplewicz, H. S. (1996). The effects of auditory stimulation on the arithmetic performance of children with ADHD and nondisabled children. Journal Learning Disabilities, 29(3), $238-246$. doi:10.1177/0022219496029

Ackerman, E. (2004). "Let's focus!" implementing ADHD interventions to increase a student's time on-task. Retrieved from https://ed.psu.edu/pds/teacher-inquiry/2004/ADHD\%20Ackerman.pdf

American Psychiatric Association. (2013). Diagnostic and statistical manual of mental disorder (5th ed.).Washington, DC : Author.

Athens, E.S., \& Vollmer, T. R. (2007). Shaping academic task engagement with percentile schedules. Journal of Applied Behavior Analysis, 40(3), 475-488. doi: 10.1901/jaba.2007.40-475

Axelrad, M, Bender, M., Bonin, L., Castle, J., Hendriksen, J. Hinton, V., \& Miller, K. (2011). Learning and Behaviour in Duchene Muscular Dystrophy for Parents and Educator. Parent Project Muscular Dystrophy. Retrieved from http://www.parentprojectmd.org/site/PageServer?pagename=Care_area_psychosocial

Axelrod, M. I., Zhe, E . J., Haugen, K. A., \& Klein, J. A. (2009). Self-management of on-task homework behavior: A promising strategy for adolescents with attention and behavior problems. School Psychology Review, 38(3), 325-333

Berk, L. E. (2006). Development through the lifespan (4th ed.). Boston, MA: Allyn \& Bacon.

Besly, K. D. (2002). Stable attributions of child behavior and parenting stress in parents of ADHD children(Master's thesis,University of North Texas, Texas, United States). Retrieved from https://digital.library.unt.edu/ark:/67531/metadc3266/

Brady, K. K. \& Kubina, R. M. (2010). Endurance of multiplication fact fluency for students with attention deficit hyperactivity disorder. Behavior Modification, 34(2), 79-93. doi: 10.1177/0145445510361331

Ciccarelli, S.K., \& Meyer, G.E.(2006). Psychology. New Jersey, NJ: Person Education.

Cipiti, A. (2010). On-task versus off-task sustained silent reading as related to reading motivation. (Master's thesis, Graduate College of Bowling Green State University, Ohio, United States). Retrieved from https://etd.ohiolink.edu/rws_etd/document/get/bgsu1269270263/inline 
DuPaul, G. J., \& Jimerson, S. R. (2014). Assessing, understanding, and supporting students with ADHD at school: Contemporary science, practice, and policy. School Psychology Quarterly, 29(4), 379-384.

Eisenberg, D, \& Schneider, H. (2007). Perceptions of academic skills of children diagnosed with ADHD. Journal of Attention Disorders, 10(4), 390-397.

Evereett, J. R. \& Cannon, B. O. (2015). Using behavioral strategies to improve skills in students with ADHD. Melmark; CHADD Annual International Conference

Fabiano, G. A., \& Pelham, W. E. (2003). Improving the effectiveness of behavioral classroom interventions for attentiondeficit/hyperactivity disorder: A case study. Journal of Emotional \& Behavioral Disorders, 11(2), 122 -132.

Feitelson, D., Kita, B., \& Goldstein, Z. (1986). effects of listening to series stories on first graders' comprehension and use of language.Research in the Teaching of English,20(4), 339-356.

Firmin, M. W. \& Phillips, A. (2009). A qualitative study of families and childrenpossessing diagnoses of ADHD. Journal of Family Issues. 20(10), 1-20. doi: 10.1177/0192513X09333709

Fraenkel, J. R., \& Wallen, N. E. (2009). How to design and evaluate research in education (7thed.). New York, NY: McGrawHill.

Frazier, T. W., Youngstrom, E. A., Glutting, J. J., \& Watkins, M. W. (2007). ADHD and achievement: Meta-analysis of the child, adolescent, and adult literatures and a concomitant study with college students. Journal of Learning Disabilities,40(1), 49-65.

Gagliano, A., Lamberti, M., Siracusano, R., Ciuffo, M., Boncoddo, M., Maggio, ...\& Germano, E. (2014). A comparison between children with ADHD and children with epilepsy in self-esteem and parental stress level. Clin Pract Epidemiol Ment Health, 10, 176-183. doi: 10.2174/1745017901410010176

Godwin, K.E., Almeda, M.V., Petroccia, M., Baker, R.S., Fisher, A.V. (2013) Classroom activities and off-task behavior in elementary school children. Poster paper. Proceedings of the Annual Meeting of the Cognitive Science Society, 228-243.

Graham-Day, J. K., Gardner, R., \& Hsin, Y. (2010). Increasing on-task behaviors of high school students with Attention Deficit Hyperactivity Disorder: Is it enough?. Education and Treatment of Children, 33(2), 205 -221.

Green, C. T., Long, D. L., Green, D. Iosif, A., Dixon, J. F., Miller, ... \& Schweitzer, J. B. (2012). Will working memory training generalize to improve off-task behavior in children with Attention-Deficit/Hyperactivity Disorder?. Neurotherapeutics, 9, 639-648. doi 10.1007/s13311-012-0124-y

Halperin, J. M., \& Healey, D. M. (2011). The influences of environmental enrichment, cognitive enhancement, and physical exercise on brain development: Can we alter the developmental trajectory of ADHD?. Neurosci Biobehav Rev, 35(3), 621634. doi:10.1016/j.neubiorev. 2010.07.006.

Harpin, V. A. (2005). The effect of ADHD on the life of an individual, their family, and community from preschool to adult life. Arch Dis Child,90(1), 2-7. doi: 10.1136/adc.2004.059006

Harpin, V., Mazzone, L., Raynaud, J. P., Kahle, J., \& Hodgkins, P. (2016). Long-term outcomes of ADHD: A systematic review of self-esteem and social function. Journal of Attention Disorders, 20(4), 295-305. doi: 10.1177/1087054713486516

Hawkins, R. O., \& Axelrod, M. I. (2008). Increasing the on-task homework behavior of youth with behavior disorders using functional behavioral assessment. Behavior Modification, 32(6), 840-859. doi: 10.1177/0145445508318846

Heath, C. L., Curtis, D. F., Fan, W., \& McPherson, R. (2015). The association between parenting stress, parenting self- efficacy, and the clinical significance of child ADHD symptom change following behavior therapy. Child Psychiatry Hum Dev., 46,118-129. doi: 10.1007/s10578-014-0458-2

Ho, S. C., Chien, W. T., \& Wang, L. (2011). Parents' perceptions of care-giving to a child with attention deficit hyperactivity disorder: An exploratory study. Contemporary Nurse, 40(1), 41-56.

Kercood, S., \& Banda, D. R. (2012). The effects of added physical activity on performance during a listening comprehension task for students with and without attention problems. IJAES, 13(1), 19-31.

Kofler, M. J. (2009). ADHD and working memory: The impact of central executive deficits and overwhelming storage/ rehearsal capacity on observed inattentive behaviour (Doctoral dissertation, University of Central Florida, Orlando, United States). Retrieved from http://stars.library.ucf.edu/etd/3952/

Kofler, M. J., Mark, D. R. \& Alderson, R. M. (2008). Quantifying ADHD classroom inattentiveness, its moderators, and variability: a meta-analytic review. Journal of Child Psychology and Psychiatry, 49(1), 59-69. doi:10.1111/j.14697610.2007.01809.x

Lantz, C., McKenna, B., Price, B., \& Stralow, D. (2007). Increasing on-task behaviour through motivational activities (Master's thesis, Saint Xavier University, Chicago, United States). Retrieved fromhttp://files.eric.ed.gov/fulltext/ED496134.pdf

Lebowitz, M. S. (2016). Stigmatization of ADHD: A Developmental Review. Journal of Attention Disorders, 20(3), $199-205$. doi: $10.1177 / 1087054712475211$

Lee, H. S., \& Song, C. S. (2015). Case study: Effects of therapeutic climbing activities wearing a weighted vest on a child with attention deficit hyperactivity disorder: a case study. Journal Phys. Ther. Sci. 27(10), 3337-3339.

Martin, G., \& Pear, J. (2007). Behavior modification: What it is and how to do it, (8thed.). New Jersey, NJ: Pearson Prentice Hall.

Mathes, M.Y., \& Bender, W.N. (1998). The effects of self-monitoring on children with attention deficit/hyperactivity disorder who are receiving pharmacological interventions. Remedial and Special Education,2, 121-128.

McInnes, A., Humphries, T., Hogg-Johnson, \& Tannock, R., (2003). Listening comprehension and working memory are impaired in Attention-Deficit Hyperactivity Disorder irrespective of language impairment. Journal of Abnormal Child Psychology, 31(4), 427-444. doi : 0091-0627/03/0800-0427/0 
Menditto, A.A., Baldwin, L.J., O'Neal, L.G., \& Beck, N.C. (1991). Social learning procedures for increasing attention and improving basic skills in severely regressed institutionalized patients. Journal of Behavior Therapy and Experimental Psychiatry, 22, 265-269.

Miller, A. C., Keenan, J. M., Betjemann, R. S., Willcutt, E., Pennington. B. F., \& Olson, R. K. (2013). Reading comprehension in children with ADHD: Cognitive underpinnings of the centrality deficit. Journal of Abnormal Children Psychology, 41(3), 473-483. doi:10.1007/s10802-012-9686-8.

Miltenberger, R. G. (2012). Behavior modification: principles and procedures, (5thed.). California, CA: Wadsworth Cengage Learning.

Miranda, A., Jarque, S., \& Tarraga, R. (2006). Interventions in school settings for students with ADHD. EXCEPTIONALITY, $14(1), 35-52$.

Paxton, J., \& Shoemake, T. (2007). Fun ways to increase children's attention span. Florida: Presentation to the 2007 ACEI Annual International Conference and Exhibition. Retrieved fromhttps://www.atu.edu/research/professionaldevelopmentgrants/06-07/jackiepaxton/Final_ReportFun_Ways_to_Increase_Children_s_Attention_Span.pdf

Pelham, W. E., \& Fabiano, G. A. (2008). Evidence-based psychosocial treatments for Attention- Deficit/Hyperactivity Disorder. Journal of Clinical Child \& Adolescent Psychology, 37(1), 184 - 214. doi: 10.1080/15374410701818681

Rabiner, D. L., Murray, D. W., Skinner, A. T., \& Malone, P. S. (2010). A randomized trial of two promising computer-based interventions for students with attention difficulties. Journal Abnormal Children Psychology, 38, 131-142. doi: 10.1007/s10802-009-9353-x

Robinson, P. W., \& Newby, T.J., \& Ganzell, S. L. (1981). A token system for a class of underachieving hyperactive children. Journal Application Behavior Analysis. 14(3), 307 -315.

Rutherford, L, E., DuPaul, G. J., \& Jitendra, A. K. (2008). Examining the relationship between treatment outcomes for academic achievement and social skills in school ages children with attention-deficit/ hyperactivity disorder. Psychology in the Schools, 45(2), 145 - 157. doi: 10.1002/pits.20283

Silverstein, S.M., Menditto, A. A., \& Stuve, P. (2001). Shaping attention span: an operant conditioning procedure to improve neurocognition and functioning in schizophrenia. Schizophrenia Bulletin, 27(2): 247-257

Student Coalition for Action in Literacy Education (SCALE). (2006). Behavior management Important facts. Retrieved fromhttp://readwriteact.web.unc.edu/files/2014/07/BehaviorManagement.pdf

Young, S., \& Amarasinghe, J. M. (2010). Practitioner review: non-pharmacological treatments for adhd: a lifespan approach. Journal of Child Psychology and Psychiatry, 51(2), 116-133. doi:10.1111/j.1469-7610.2009.02191.x

Zentall, S.S., Falkenberg, S. D., \& Smith, L. B. (1985). Effect of color stimulation on the copying performance of attention problem adolescents. Journal of Abnormal Child Psychology, 13, 501 -511. 